\title{
Use of fluorescence spectroscopy to control ozone dosage in recirculating aquaculture systems
}

Spiliotopoulou, Aikaterini; Martin, Richard; Pedersen, Lars-Flemming; Andersen, Henrik Rasmus

Published in:

Water Research

Link to article, DOI:

10.1016/j.watres.2016.12.036

Publication date:

2017

Document Version

Peer reviewed version

Link back to DTU Orbit

Citation (APA):

Spiliotopoulou, A., Martin, R., Pedersen, L-F., \& Andersen, H. R. (2017). Use of fluorescence spectroscopy to control ozone dosage in recirculating aquaculture systems. Water Research, 111, 357-365.

https://doi.org/10.1016/j.watres.2016.12.036

\section{General rights}

Copyright and moral rights for the publications made accessible in the public portal are retained by the authors and/or other copyright owners and it is a condition of accessing publications that users recognise and abide by the legal requirements associated with these rights.

- Users may download and print one copy of any publication from the public portal for the purpose of private study or research.

- You may not further distribute the material or use it for any profit-making activity or commercial gain

- You may freely distribute the URL identifying the publication in the public portal

If you believe that this document breaches copyright please contact us providing details, and we will remove access to the work immediately and investigate your claim. 


\title{
Use of fluorescence spectroscopy to control ozone dosage in recirculating aquaculture systems
}

\author{
Aikaterini Spiliotopoulou, ${ }^{1,2}$, Richard Martin ${ }^{3}$, Lars-Flemming Pedersen ${ }^{4}$, \\ Henrik R. Andersen ${ }^{1 *}$
}

\footnotetext{
${ }^{1}$ Department of Environmental Engineering, Technical University of Denmark, Bygningstorvet 115, 2800 Kongens Lyngby, Denmark

${ }^{2}$ OxyGuard International A/S, Farum Gydevej 64, 3520 Farum, Denmark

${ }^{3}$ Water ApS, Farum Gydevej 64, 3520 Farum, Denmark

${ }^{4}$ Technical University of Denmark, Section for Aquaculture, The North Sea Research Center, P.O.Box 101, 9850 Hirtshals, Denmark *Corresponding author: hran@env.dtu.dk
}

\section{Graphical abstract}
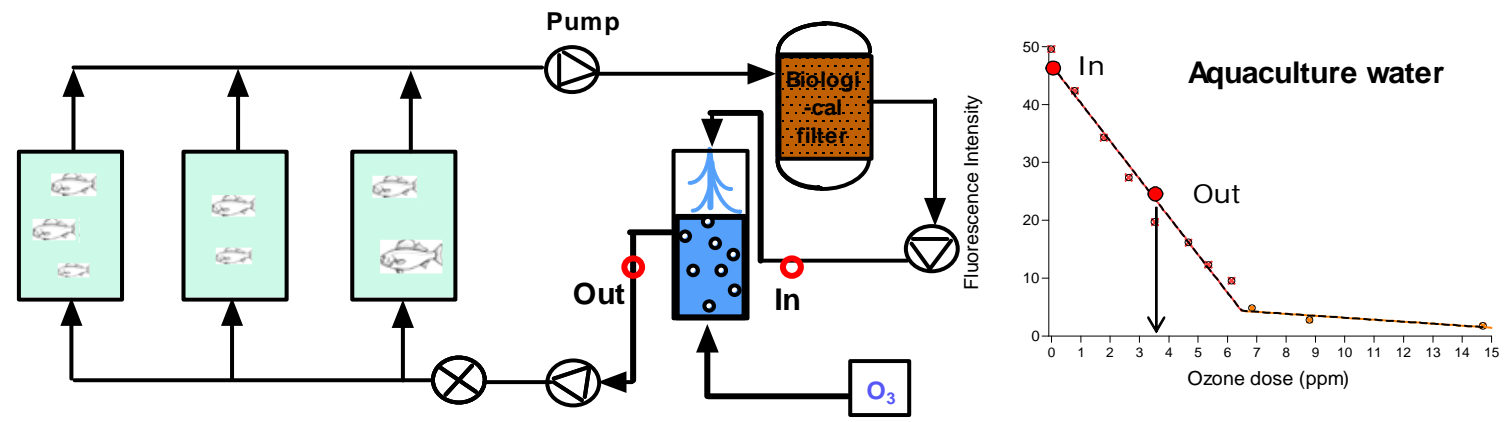

\section{Highlights}

- Ozonation reduces natural fluorescence intensity in aquaculture water

- Fluorescence intensity is highly sensitive to ozone in the 0-5 $\mathrm{mg} \mathrm{O}_{3} / \mathrm{L}$ range

- Offline fluorescence can measure $\mathrm{O}_{3}$ dosage in full-scale ozone systems

- Online fluorescence sensors might control ozone dosage in ozonation systems

Abstract The aim of this study was to investigate the potential of fluorescence spectroscopy to be used as an ozone dosage determination tool in recirculating aquaculture systems (RASs), by studying the relationship between fluorescence intensities and dissolved organic matter (DOM) degradation by ozone, in order to optimise ozonation treatment. Water samples from six different Danish facilities (two rearing units from a commercial trout RAS, a commercial eel RAS, a pilot RAS and two marine water aquariums) were treated with different $\mathrm{O}_{3}$ dosages $(1.0-20.0 \mathrm{mg} / \mathrm{L}$ ozone) in bench-scale experiments, following which fluorescence intensity degradation was eventually determined. Ozonation kinetic experiments showed that RAS water contains fluorescent organic matter, which is easily oxidised upon ozonation in relatively low concentrations $\left(0-5 \mathrm{mg} \mathrm{O}_{3}\right.$ /L). Fluorescence spectroscopy has a high level of sensitivity and selectivity in relation to associated fluorophores, and it is able to determine accurately the ozone demand of each system. The findings can potentially be used to design offline or online sensors based on the reduction by ozone of natural fluorescent-dissolved organic matter in RAS. The suggested indirect determination of ozone delivered into water can potentially contribute to a safer and more adequate ozone-based treatment to improve water quality.

Keywords Online fluorescence sensor, natural fluorescence, ozonation, recirculating aquaculture, ozone dosage determination.

Abbreviations Recirculating aquaculture system (RAS), Dissolved organic matter (DOM), Organic matter (OM), Dissolved organic carbon (DOC). 


\section{Introduction}

The water in recirculating aquaculture systems (RASs) is characterised by the accumulation of certain organic and inorganic compounds (Bullock et al., 1997; Davidson et al., 2011). These compounds are generated by the feed delivered (amount and composition) and the subsequent dissolved and particulate excreta of fish (Dalsgaard and Pedersen, 2011). Depending on treatment units, feed intensity and feed loading, slow/non-degradable dissolved organic compounds (DOC) (i.e. humic substances, lignins), nitrate and micro-particles are typically present at elevated levels (Davidson et al., 2009). With a high retention time and a continuous supply of bioavailable dissolved organic matter (DOM), the growth and abundance of bacteria can reach levels that inhibit fish and system performance (Bullock et al., 1997). Attempts to address such suboptimal conditions are typically carried out by the implementation of additional mechanical and biological treatments (Summerfelt et al., 2009) or by chemical treatment.

The successful management of a RAS relies, among others, on the control of DOM (Hambly et al., 2015). Fluorescence spectroscopy has been used widely for off- and online monitoring in water treatment applications, in order to optimise processes (e.g. aeration) (Reynolds and Ahmad, 1997) and to identify deteriorating agents (Hudson et al., 2007). It is an inexpensive and simple tool which is able to determine rapidly and accurately (Hudson et al., 2007; Henderson et al., 2009) the presence of DOM in wastewater effluent (Carstea et al., 2016), drinking water (Cumberland et al., 2012), fresh water (Baker, 2001;), seawater (Coble, 1996; Chen, 1999; Conmy et al., 2004; Baker \& Spencer, 2004) and RAS water (Hambly et al., 2015). Several other parameters of importance for the efficiency of RAS, such as total organic carbon (TOC) (Carstea et al., 2016), biological oxygen demand (BOD) (Hudson et al., 2008), phosphate, nitrogen-based compounds (Baker and Inverarity, 2004) and microbial abundances (Cumberland et al., 2012), can be also identified by fluorescence. Therefore, it is promoted as a promising real-time monitoring technique to determine DOM, thus optimising RAS management (Hambly et al., 2015).

The optical attributes of DOM are the result of a complex amalgam of chromophores (molecules that absorb light energy) and fluorophores (molecules that re-emit the absorbed light); expressed by a unique excitation/emission wavelength pair ( $\left.\lambda_{\text {excitation, emission }}\right)$ for each component, referred to as a component's "fluorescence fingerprint" (Larsen et al., 2010). In RASs, three spectrum regions have

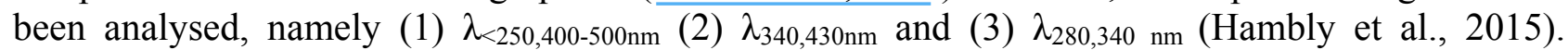
Although, the transition pairs in this study originally come from a wastewater review study (Hudson et al., 2007), their range has been limited to more specific wavelength pairs (Table 1). The

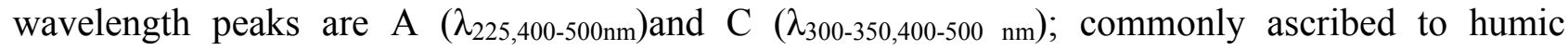
materials (Aiken, 2014), $\mathrm{T}_{1}\left(\lambda_{280,350 \mathrm{~nm})}\right)$ and $\mathrm{T}_{2}\left(\lambda_{225,350 \mathrm{~nm})}\right)$ globally correlated with BOD, and B $\left(\lambda_{225,305 \mathrm{~nm}}\right)$ (Hudson et al., 2007). The latest are related to microbial activity (Cumberland et al., 2012) and therefore to organic matter bioavailability.

Table 1: Excitation, emission wavelength pair for fluorophores based on Hudson et al. (2007).

\begin{tabular}{cc}
\hline $\begin{array}{c}\text { Fluorophore name } \\
(\text { Coble, 1996) }\end{array}$ & $\begin{array}{c}\text { Excitation, Emission } \\
\text { wavelength (nm) }\end{array}$ \\
\hline Peak B1 & 231,315 \\
Peak T1 & 231,360 \\
Peak A & 249,450 \\
Peak B2 & 275,310 \\
Peak T2 & 275,340 \\
Peak C & 335,450 \\
\hline
\end{tabular}

Ozonation is a well-established technology in multiple water treatment applications and has indisputable benefits for water quality (Powell and Scolding, 2016). Furthermore, it is a strong 
oxidising agent and reacts rapidly with non-biodegradable DOM, converting it into easier biodegradable molecules. When ozone is added to water, protein degradation is enhanced, while water clarity, UV transparency (Bullock et al., 1997; Davidson et al., 2011) and the processes of coagulation, filtration (Summerfelt \& Hochheimer, 1997; Antoniou \& Andersen, 2012) and nitrification are improved (Gonçalves and Gagnon, 2011). Moreover, it is bactericidal, parasiticidal and virucidal (Bullock et al., 1997; Summerfelt et al., 2004; Powell et al., 2015), contributes to odourant reduction (geosmin and 2-methylisoborneol (MIB)), improves the taste of cultivated aquaculture species (Gonçalves and Gagnon, 2011) and eventually enriches water with oxygen.

If ozone addition is not correctly applied nor analytically verified, under-dosing or overdosing may occur. Ozone (due to overdosing) might reach culture tanks, and adversely affect cultured species (Bullock et al., 1997), as it is considered toxic to a wide range of marine and freshwater organisms at concentrations above $0.01 \mathrm{mg} / \mathrm{L}$ to $0.1 \mathrm{mg} / \mathrm{L}$ (Gonçalves \& Gagnon, 2011) by harming the gills and the tissues of fish and eventually leading to death. Ozonation is suspected to form several byproducts, including hypobromous acid in the case of marine water (Grguric et al., 1994; Wert et al., 2008), aldehydes and carboxylic acids, which are carcinogens (Matsuda et al., 1992). The risk of losing fish and the subsequent high costs limit the aquaculture industry's interest in using ozone (Bullock et al., 1997). Thus, to prevent any undesirable side effects, it is necessary to monitor ozone demand.

Residual ozone determination in water is usually achieved by employing an expensive test kit or complicated chemical methods which require skilled operators working in laboratory conditions (Bader and Hoigné, 1981). It can also be determined indirectly by measuring the formation of ozonated by-products (OBP) in marine water, a complicated method due to water's chemistry (Tango and Gagnon, 2003). Potentiometric principle probes are expensive, while the more traditional oxidation/reduction potential (ORP) sensors are not specific (they do not distinguish, for example, ozone from chlorine), in presence of high ozone concentrations tend to fail and, last but not least, do not actually measure ozone (Bullock et al., 1997). Despite these flaws, a number of methods can be used to determine dissolved ozone in water; what is actually lacking is a technique that can determine the amount of ozone delivered into water.

The most obvious effect of ozone in organic-loaded water samples is decolourisation. Fluoropores are more reactive than DOC, and so they are oxidised faster through the addition of ozone (Liu et al., 2015), thus affecting fluorescence intensity (Korshin et al., 1999) and consequently making spectra-based methods the most suitable for online monitoring, due to their high sensitivity and ease of use (Hudson et al., 2007; Li et al., 2016). Electrophilic oxidants, such as ozone and chlorine in general break down chromophoric groups within the structure and decrease fluorescence, while advanced oxidation breaks down the DOM into smaller chromophoric fractions, thereby enhancing fluorescence (Henderson et al., 2009).

The limitation factors which prevent UV-VIS spectroscopy to determine delivered ozone in RASs are the chemical reagents involvement (indigo method) and the personnel presence to conduct the measurement. Fluorescence on the contrary is a straight forward measurement, and previous studies (e.g. Li et al., 2016; Jin et al., 2016) have documented high correlation between the two methods. The numerous fluorescent properties of aquatic DOM, its high reactivity with ozone and the risk of ozone's presence in culture tanks raise questions related to the ability of fluorescence to measure indirectly the delivery of ozone into water. This study attempts to evaluate the potential of fluorescence spectroscopy as an ozone dosage determination tool in water, by studying the relationship between fluorescence intensities and DOM degradation by ozone, in order to prevent accidental overdose due to a malfunctioning ozone generator. 


\section{Material and Methods}

2.1. Reagents

All chemicals used in this study were purchased from Sigma Aldrich Denmark ApS and were used as received.

\subsection{Origin of water samples}

Water samples were collected from two commercial RAS fish farms, a pilot RAS and two aquaria a public aquarium (The Blue Planet, which is the national public aquarium in Denmark) and an aquarium in an amusement park (Tivoli) - and used for experiments without any further treatment the following day. All the facilities are located in Denmark, and they varied greatly in terms of installation, water treatment technology, cultivated species and purpose. The first fish farm was a model trout farm (raceway), receiving surface water from an adjacent stream and equipped with airlifts, mechanical contact filters and biological moving-bed biofilters. Samples were taken from two different locations in this specific RAS - at the outlet from the fingerling production unit and from the grow-out unit. The second RAS cultivated eels at relatively low densities and was equipped with additional water treatment technologies, including oxygen cones, drum filters, a trickling filter for aeration/degassing and nitrification and in-line ozonation. Water was sourced from a local water supply (a well). The pilot-scale RAS was $8.5 \mathrm{~m}^{3}$ and stocked with approximately $150 \mathrm{~kg}$ trout with stable feed loading ( $1 \mathrm{~kg}$ feed/day per $1 \mathrm{~m}^{3}$ make-up water). The samples from the two aquaria were saline (either directly from the sea or artificial) and were collected from the backwash of filters in the ocean tank (The Blue Planet) and the shark show tank (Tivoli), while inline ozonation and advanced water treatment technologies were installed in both units.

\subsection{Quantification}

\subsubsection{Determination of ozone concentration}

Ozone concentration was determined using the indigo method (Bader and Hoigné, 1981). The absorbance of the unreacted indigotrisulphonate was measured at $600 \mathrm{~nm}$ with a spectrophotometer (Hach Lange). Ozone concentration was determined by comparing the absorbance of a blank with the sample, and using DA $=-200001 /(\mathrm{cm}$ mol ozone added per L).

\subsubsection{Organic carbon determination}

A Shimadzu ASI-V UVC/Persulphate analyser was used to quantify non-volatile organic carbon in the raw samples. The injected sample volume was $3.00 \mathrm{~mL}$ and a calibration curve with potassium hydrogen phthalatestandards from 50 to $2000 \mu \mathrm{g} / \mathrm{L}$ was determined $\left(\mathrm{R}^{2}=0.9994\right)$. The quantification limit of the method was $50 \mu \mathrm{g} / \mathrm{L}$.

\subsubsection{Fluorescence}

Fluorescence intensity identifies the presence and the amount of specific molecules in a medium and in this case was determined by a fluorimeter (Cary Eclipse, Varian) and expressed in arbitrary units (Au.). To increase the accuracy and responsiveness of the potential online sensor, six transition pairs were selected and used; the excitation wavelength was ranging from $213 \mathrm{~nm}$ to 335 $\mathrm{nm}$ while the emission wavelength was from $310 \mathrm{~nm}$ to $450 \mathrm{~nm}$. Samples were transferred in a quartz cuvette and subjected to further analysis, while there was no need for dilution. According to Hudson et al. (2007), the range of DOM that fluorescence can be applied without any dilution, lays from 1-100ppm, highlighting that when DOM is lower than 20ppm the effect is negligible (Vodacek and Philpot, 1987) - 20ppm is the most heavily organic loaded sample in our case.

Although the ease of data collection and the potential applications; fluorescence is a complicated method. According to Aiken (2014), fluorescence signal is affected by chemical (inner filter effects, $\mathrm{pH}$, temperature, redox status) and nonchemical (instrumental inefficiencies and variability) factors. In case of turbidity, samples were left to settle in (simulating the natural suspended solid removal in 
full-scale systems), prior to the fluorescence scan, while $\mathrm{pH}$ and temperature were the same for all the samples. The technique is non-destructive and requires no sample preparation.

\subsection{Ozonation}

The experimental set-up for ozonation was based on a $20 \mathrm{~g} / \mathrm{h}$ ozone generator from $\mathrm{O}_{3}$-Technology AB (Vellinge, Sweden), supplied with dry oxygen gas. In order to create the ozone stock solution, the generated ozone was dispersed through a diffuser in a pressurised collection bottle containing ultra-pure water, which was submersed in an ice bath to increase ozone solubility further. To achieve higher ozone solubility, a manometer and a valve were placed after the collection bottle, where a pressure of 1.2 barG was established. Ozone concentration in the stock solution ranged between 70 and $110 \mathrm{mg} / \mathrm{L}$. Water samples $(50 \mathrm{~mL})$ were spiked with a volume of ozone stock solution (i.e. $2 \mathrm{~mL}$ ), as described in Hansen et al. (2016). Ozone dosage was determined by adding the same amount of ozone as in the sample, in acidified MilliQ water bottles of $50 \mathrm{~mL}$ total volume, containing a $5 \mathrm{~mL}$ phosphate buffer and a sufficient amount of potassium indigotrisulphonate (Antoniou et al., 2013). Several ozone dosages were added, ranging from 0 to $20 \mathrm{mg} \mathrm{O} / \mathrm{L}$.

\subsection{Experiments}

Six water matrices were subjected to ozonation, to provide a representative and comprehensive investigation of the correlation between fluorescence indices and the degradation of DOM. Experiments were conducted in bench-scale laboratory conditions, in order to ensure a controlled environment. The main principle was to deliver different ozone dosages to water samples, as described in Section 2.4, and measure fluorescence degradation. After ozonation, the samples were stored at $15^{\circ} \mathrm{C}$ for an hour - enough time to ensure ozone absence, since its lifetime found experimentally to be limited to just a few minutes. In each experimental batch, one sample was not spiked with ozone, in order to provide a reference value (blank), but it was subjected to the same experimental conditions as the rest of the samples, e.g. retention time and temperature. Afterwards, absorbance was measured at $600 \mathrm{~nm}$ (Bader and Hoigné, 1981) and compared to the blank. Ozonation experiments and TOC analysis were based on a single sample (no replicates). The purpose of the experiment was to investigate fluorescence sensitivity in relation to ozone in correlation with oxidised DOM in different aquatic environments, and therefore it is believed that is more important to have several data points describing the regression line than having several replicates. Obtained data were analysed using MS Excel and Prism Graph Pad 5.0.

\section{Results and discussion}

\subsection{Water characterisation}

The water samples varied greatly in terms of physicochemical characteristics (Table 2).

Table 2: Water sample parameters.

\begin{tabular}{lcc}
\hline & DOC $(\mathrm{mg} / \mathrm{L})$ & $\mathrm{pH}$ \\
\hline Commercial trout RAS (grow-out unit) & 9.4 & 7.4 \\
Commercial trout RAS (fingerling unit) & 9.6 & 7.5 \\
Pilot RAS (trout) & 14.4 & 7.2 \\
Commercial eel RAS & 20.3 & 6.9 \\
Tivoli (shark show tank) & 0.34 & 8.0 \\
The Blue Planet (ocean display tank) & $<0.05$ & 7.6 \\
\hline
\end{tabular}

Dissolved organic carbon was observed to differ between the facilities, due to different system configurations, stocking density, feed loading and quantity composition. In the two aquaria, DOC was extremely low (low fish density and an advanced filtration system, including ozonation employed to achieve high water transparency). In the commercial trout RASs and the pilot RAS, DOC was increased, at approximately $9.5 \mathrm{mg} / \mathrm{L}$ (an average of the two sampling locations) and 14.4 
$\mathrm{mg} / \mathrm{L}$, respectively, but this was lower than in the commercial eel RAS, which stood at $20.3 \mathrm{mg} / \mathrm{L}$. The water treatment systems in commercial RASs cultivating eel and trout operate at higher pollution concentrations, as larger volumes have to be treated cost-effectively. Conversely, aquaria implement state-of-the-art water treatment technology since the high water clarity is of great importance and therefore, the capital and operational costs are increased. Additionally, the commercial trout RAS was also influenced by environmental factors potentially varying/enhancing DOM concentrations in relation to the composition of the water quality of the creek. The $\mathrm{pH}$ values were neutral, ranging from 6.9 to 8.0 .

\subsection{Initial fluorescence characterisation}

Water samples derived from the two commercial and pilot RASs consisted mainly of $\mathrm{A}$ and $\mathrm{C}$ peaks (Table 1) (Figures 1a-d focusing on $0 \mathrm{mg} \mathrm{O}_{3} / \mathrm{L}$ dosage), which are correlated highly with TOC (Carstea et al., 2010). On the contrary, the peaks $\mathrm{T}$ and $\mathrm{B}$, were less pronounced yet present (Figures 1a-d focusing on $0 \mathrm{mg} \mathrm{O} \mathrm{O}_{3} / \mathrm{L}$ dosage). Fluorescent DOM in aquariums was detected in significantly lower intensities and therefore it is difficult to conclude which peak dominated (Figures 1e and 1f, focusing on $0 \mathrm{mg} \mathrm{O}_{3} / \mathrm{L}$ dosage). Based on this study's findings, it is clear that fluorescent OM exists in RASs, while the fluorescent components are distinct. It can also be concluded that water samples from commercial RASs and the pilot RAS facility are the most OMloaded, and the two aquariums the least so in this regard.

Fluorescence peaks similar to our findings were published in wastewater and municipal wastewater studies (Carstea et al., 2016) with the A and C peaks being better studied than the peaks $\mathrm{T}$ and $\mathrm{B}$ (which are associated commonly with tryptophan and tyrosine, respectively) (Hudson et al., 2007). Several wastewater studies also suggest that microbial-derived $\mathrm{T}$ and $\mathrm{B}$ types of fluorescence are enhanced (Baker \& Inverarity, 2004; Carstea et al., 2010). Therefore, our initial hypothesis regarding the existence of fluorescent OM in RAS water is supported by both the obtained data and by a currently published study (Hambly et al., 2015).

\subsection{Effect of Ozone dosage on fluorescence intensity}

Ozonation had a substantial impact on fluorescence intensity. The degradation of fluorophores in the investigated samples, when subjected to ozonation, suggests one-phase decay (Figure 1) utilizing the Function 1.

$\mathrm{Y}=\left(\mathrm{Y}_{0}-\text { Plateau }\right)^{*} \exp ^{\left(-\mathrm{K}^{*} \mathrm{X}\right)}+$ Plateau

Where, $\mathrm{X}$ : ozone dosage, $\mathrm{Y}$ : starts at $\mathrm{Y}_{0}$ and decays (with one phase) down to Plateau, $\mathrm{Y}_{0}$ and Plateau: Same units as $\mathrm{Y}, \mathrm{K}$ : rate constant.

Peaks $\mathrm{A}$ and $\mathrm{C}$ were reduced to half in both commercial RASs (Figures 1a,1b,1d) when approximately $5 \mathrm{mg} \mathrm{O}_{3} / \mathrm{L}$ was dosed, while for the pilot RAS and aquariums fluorescence was halved by much lower dosages $\left(<1 \mathrm{mg} \mathrm{O}_{3} / \mathrm{L}\right.$ ) (Figures 1c,1e,1f). When adding the same ozone dosage ( $5 \mathrm{mg} \mathrm{O}_{3} / \mathrm{L}$ ) in all the studied cases, the already low-intensity of peaks $\mathrm{B}$ and $\mathrm{T}$ was almost non-existent (Figure 1). The fact that $\mathrm{A}$ and $\mathrm{C}$ peaks are easier to detect than $\mathrm{B}$ and $\mathrm{T}$ peaks, makes them the most promising candidates for a future industrial application (Li et al., 2016).

Based on our findings, it can be concluded further that, for RASs, relatively low ozone dosages are sufficient to increase water clarity by removing DOM. It has been reported that A and C peaks, when subjected to ozonation, are unaffected, while for the B and T peaks a decrease in intensity is typical (Henderson et al., 2009). 

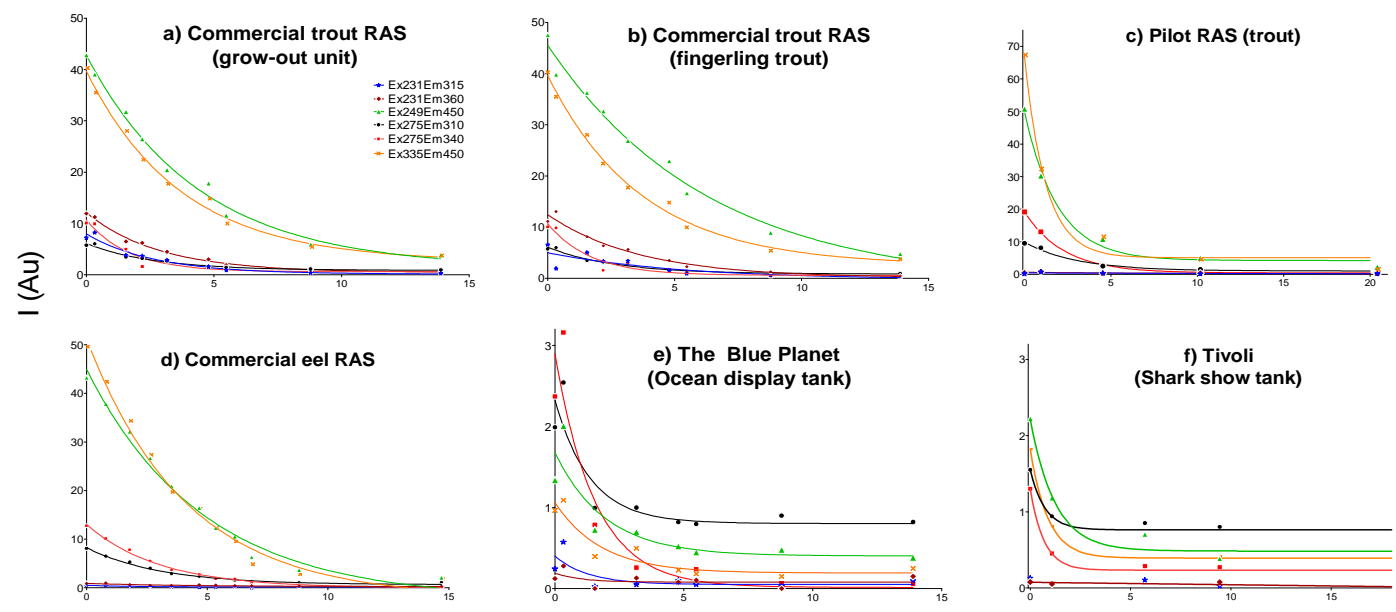

Ozone dose (ppm)

Figure 1: Characterisation of the ozonation effect on aquaculture water fluorescence.

High ozone dosages up to $20 \mathrm{mg} \mathrm{O} / \mathrm{L}$ were then applied, in order to investigate the behaviour of fluorescence in high ozone concentration exposure and to see if it would finally be completely removed. The addition of $15 \mathrm{mg} \mathrm{O} / \mathrm{L}$ or more significantly reduced fluorescence intensity but was not able to oxidise it entirely. More specifically, fluorescence in the commercial and pilot RASs reached a reduction rate ranging from $90 \%$ to $97.7 \%$ (Figures 1a-d), while fluorescence reduction in the aquariums was in the order of $60 \%$ and $82.3 \%$, respectively (Figures 1e,1f). Thus, a low fluorescence activity remained in water, which did not react with ozone. Possible being fully oxidised inorganic solutes in water.

\subsection{Fluorescence-based response curve}

\subsubsection{Linearity and range}

If fluorescence is used to control ozone dosage, a calibration curve has to be established to take into account the nature of responsiveness to ozone. The calibration of an instrument is a factor that should be considered, to ensure results' repeatability and reliability. The curve and the range are crucial components used to define the calibration properties.

An attempt to create a calibration curve was made by utilising the data presented in Section 3.3. The elimination of the wavelengths describing the fluorescence degradation upon ozonation is vital for the manufacturing of a real-time measurement sensor. Among the six studied wavelengths only two were selected to be further investigated - these with the best fitting.

Based on our data, it seems unlikely that a single straight line would fit; therefore, two straight lines were fitted utilizing the Function 2.

$\mathrm{Y}=\mathrm{IF}\left(\mathrm{x}<\mathrm{xo}, \mathrm{Y} 1+\right.$ slope $^{*} \mathrm{X}, \mathrm{Y} 2+$ slope $\left.2 * \mathrm{X}\right)$

(Function 2)

Figures 2a-f depict the fit lines for the peak $C\left(\lambda_{335,450}\right)$, while Figures $2 \mathrm{~g}-1$ apply to peak B2 $\left(\lambda_{275,310}\right)$. In all cases, the two lines, describing each curve, corresponded nicely to the obtained data. The break that defined the two straight lines was chosen based on the best fit. The accuracy of the fit derived from the multiple data point fitting being supported by the high $\mathrm{R}^{2}$ values. The nonlinear behaviour of fluorophores in natural samples has been adequately addressed by common approaches in order to explain the environmental and ecological significance of DOM fluorescence (Aiken, 2014). 

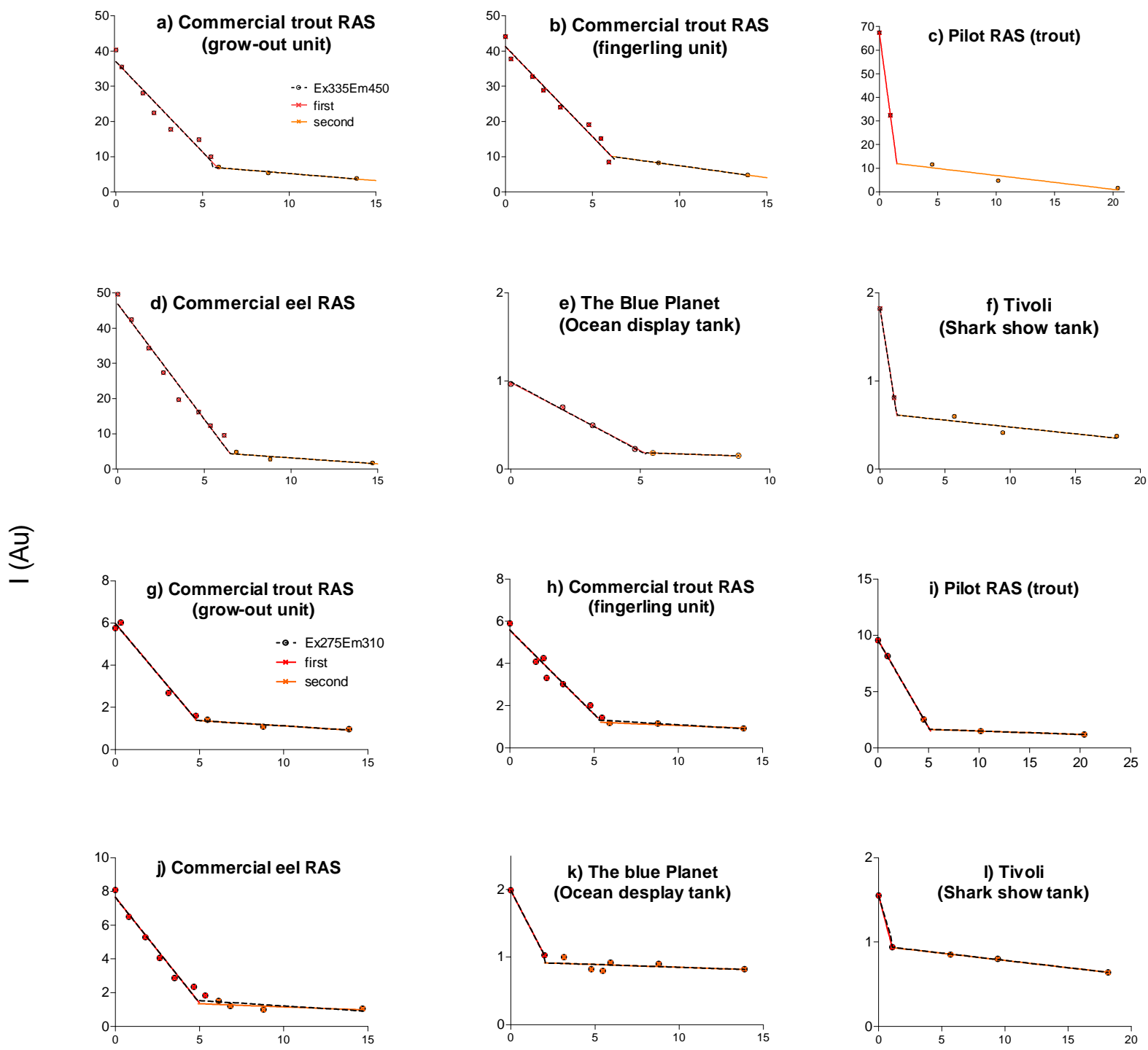

Ozone dosage (ppm)

Figure 2: Fluorescence - ozone response curves for Peak C (2a-f) and Peak B2 (2g-I).

\subsubsection{Likeness of response among the different types of water}

When continuous treatment with ozone is applied in a closed system (e.g. a RAS) water quality will improve to an apparent steady state with the production of organic matter that can be oxidised. This might however vary in the short term e.g. as feed is applied, fish stocking or temperature changes. Thus, it was hypothesised that a low-range calibration curve from 0 to $5 \mathrm{mg} \mathrm{O} / \mathrm{L}$ might be able to describe fluorescence removal by ozone in RASs (Figure 3). Focusing on each one of the cases individually, we note a nice linear regression with high $\mathrm{R}^{2}$ for both $\mathrm{C}$ (Figures $3 \mathrm{a}-\mathrm{f}$ ) and $\mathrm{B}$ peaks (Figures 3g-1), thereby indicating high accuracy. However, since there is a second line (Figure 2), these calibration curves have limited capacity in detecting extremely low fluorescent indices when higher ozone dosages were injected ( 5 to $20 \mathrm{mg} \mathrm{O} / \mathrm{L}$ ). The slopes suggest that the peak $\mathrm{C}$ in the commercial RASs (Figures 3a-d) is more vulnerable and sensitive to ozonation than the peak B2 (Figures 3g-j). However, the great variation which is observed when comparing the slopes of the curves for both fluorescent components, among the different water samples, makes it unlikely that a universal calibration curve will be created for a sensor, which will directly convert fluorescence 
intensity into the applied ozone dosage $\left(\mathrm{mg} \mathrm{O}_{3} / \mathrm{L}\right)$, since there is no fixed ratio between ozone dosage and fluorescence destruction. Similarly, Li et al. (2016) found it difficult to compare intensities across wastewater studies, due to arbitrary fluorescence units, in which case, in order to compare results directly among sensors, correction factors have to be applied (Henderson et al., 2009). This challenge surrounding system-specific calibration requires further investigation.
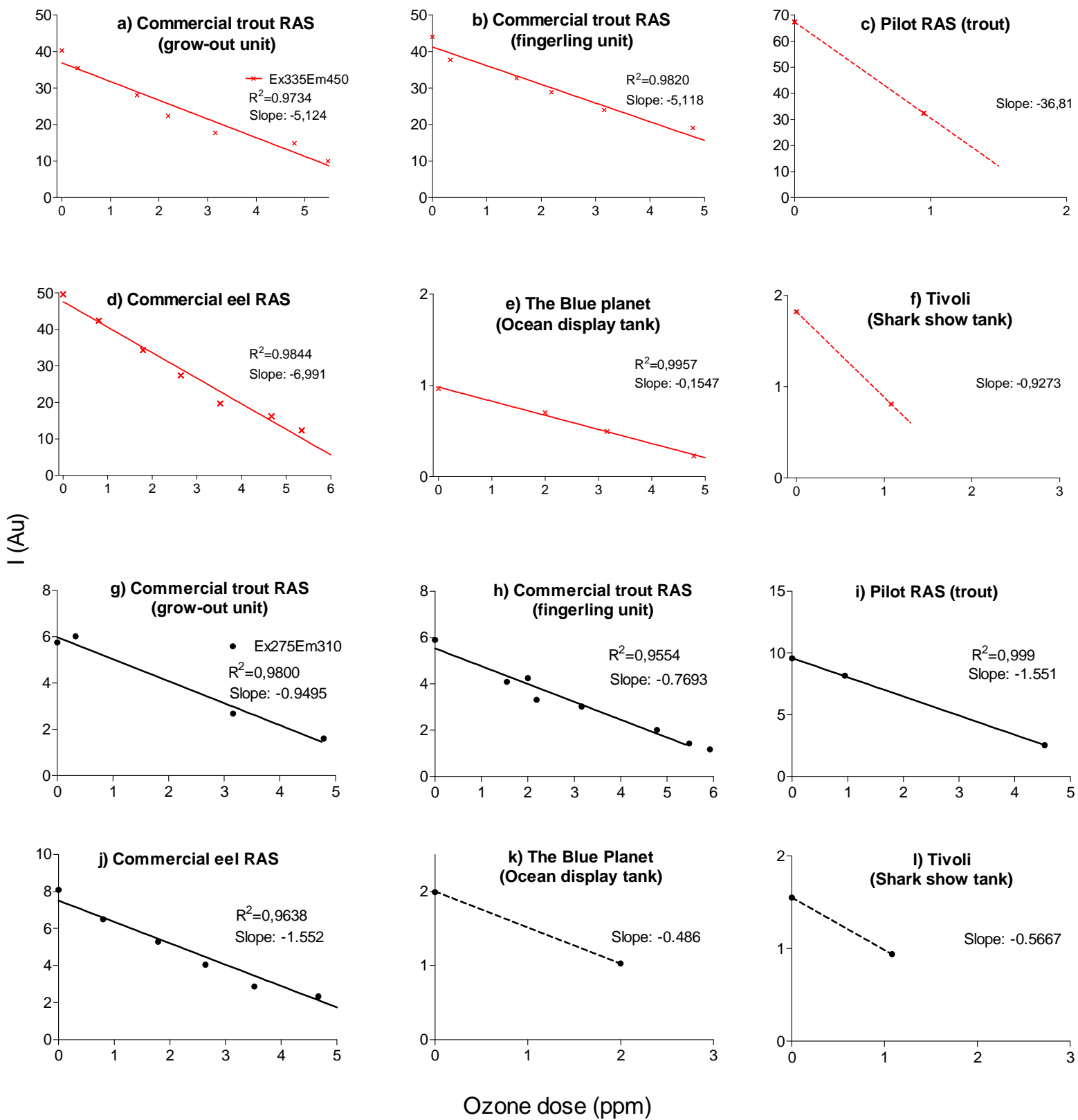

Figure 3: C peak (3a-f) and B2 peak (3g-i) calibration curves. The dotted line in graphs $3 c, f, k, I$ represent the trend, since there was lack of sufficient data to better define the curve.

\subsection{Application of fluorescence for ozonation systems}

Simple and easily measurable parameters, providing information regarding the concentration and reactivity of DOM, will lead to better designed systems and encourage better management practices. Deviations from baseline figures can be identified, as can corresponding actions, and dosing the appropriate ozone concentration will also be facilitated ( $\mathrm{Li}$ et al., 2016). Currently, there 
are fluorescence sensors in the market operating in these wavelengths. The intention of the present study was to investigate if a universal sensor utilising fluorescence removal can control ozone dissolved in water. If the slopes were the same among the different water samples, then the removal of fluorescence intensity would be directly convertible to ozone dosage. Alternatively, several potential industrial applications are suggested and seem to be promising. The blue dots represent the sampling location in the case of offline ozone control (Figure 4a), while the red dots indicate an online sensor installation in the system (Figures $4 \mathrm{~b}$ and $4 \mathrm{c}$ ).

\subsubsection{Determination of delivered ozone dosage}

A persistent problem in the use of ozone systems is the determination of the actual dosage of ozone. The standard method involves applying dual ozone sensors on the gas flow from the ozone generator and off gas flow from the ozone-water contact chamber. However, such sensors might cost more than ozone systems, depending on the size of the ozone system used in aquaculture. A potential way to quantify ozone system performance, without any sensor installation, would be to collect grab water samples before and after ozone injection, transfer them to the laboratory (sampling location as shown in Figure 4a) and then create a calibration curve for the specific facility (similarly to the current study (Figures 2 and 3)). Based on the calibration curve, the actual ozone dosage in the water can be read as fluorescence for the specific system and then be directly converted to ozone concentration. This approach allows for checking periodically the ozone generator and comparing the obtained data with the manufacturer's specifications, thus ensuring the optimal operation of the equipment, which consequently has a monetary value.

\subsubsection{Online control in recirculation systems}

Dissolved organic matter is a key parameter for properly designing an ozonation system, since it dictates ozone demand. An online control system, based on a single or few fluorescence sensors, depending on system's complexity, will ensure that the ozone concentration delivered in water will be within predetermined safety level. A fluorescence intensity within the calibration curve will be chosen as a control point (in the present case the limit is fluorescence intensity of $25 \mathrm{Au}$. as illustrated in Figure 4b), and would be accepted to fluctuate within a predetermined limit. When fluorescence intensity exceeds the range, ozone will be dosed accordingly in order to maintain the fluorescents within the limits. With this approach, the ozone demand is well defined and therefore excess of injected ozone into water is prevented. Although the water will have high clarity, the disinfection will be limited but enough to support healthy cultivated species. An additional benefit of the suggested sensor is the low operational cost since only the required ozone dosage will be injected.

\subsubsection{Online control in flow through systems}

Ozone dosage control, based on fluorescence spectroscopy, is a technique used not only in RASs, but also in other water treatment facilities, e.g. drinking water, wastewater treatment plans, etc. which are so-called "flow-through" systems (Figure 4c). Depending on a facility's needs, an online sensor will be installed in the inlet of the facility evaluating influent water quality in terms of fluorescence intensity. Based on the fluorescence of this influent water, an ozone generator will be adjusted accordingly, in order to oxidise pesticides and miscellaneous micro-pollutants and deactivate pathogens that the water stream might carry and which may possibly be harmful to the facility (pertinent to drinking water and RAS applications). A second sensor would work in conjunction with the ozone generator, ensuring that there is no residual ozone left behind.

Alternatively, the same set up can be installed in the outlet of the facility, before the water is discharged to the environment, similarly to Figure 4c, in order to ensure that chemical compounds used within the facility (e.g. antibiotics or other chemicals) are oxidised and consequently absent 
from the water stream. The purpose of this approach is to constantly maintain fluorescence differences, independent on inlet water quality (dilution, due to rain, will cause a relocation of the curve (blue line in Figure 4c) but the intensity difference will remain the same). If fluorescence intensity is lower than the predetermined fluorescence level in the effluent, then less ozone should be fed into the system.
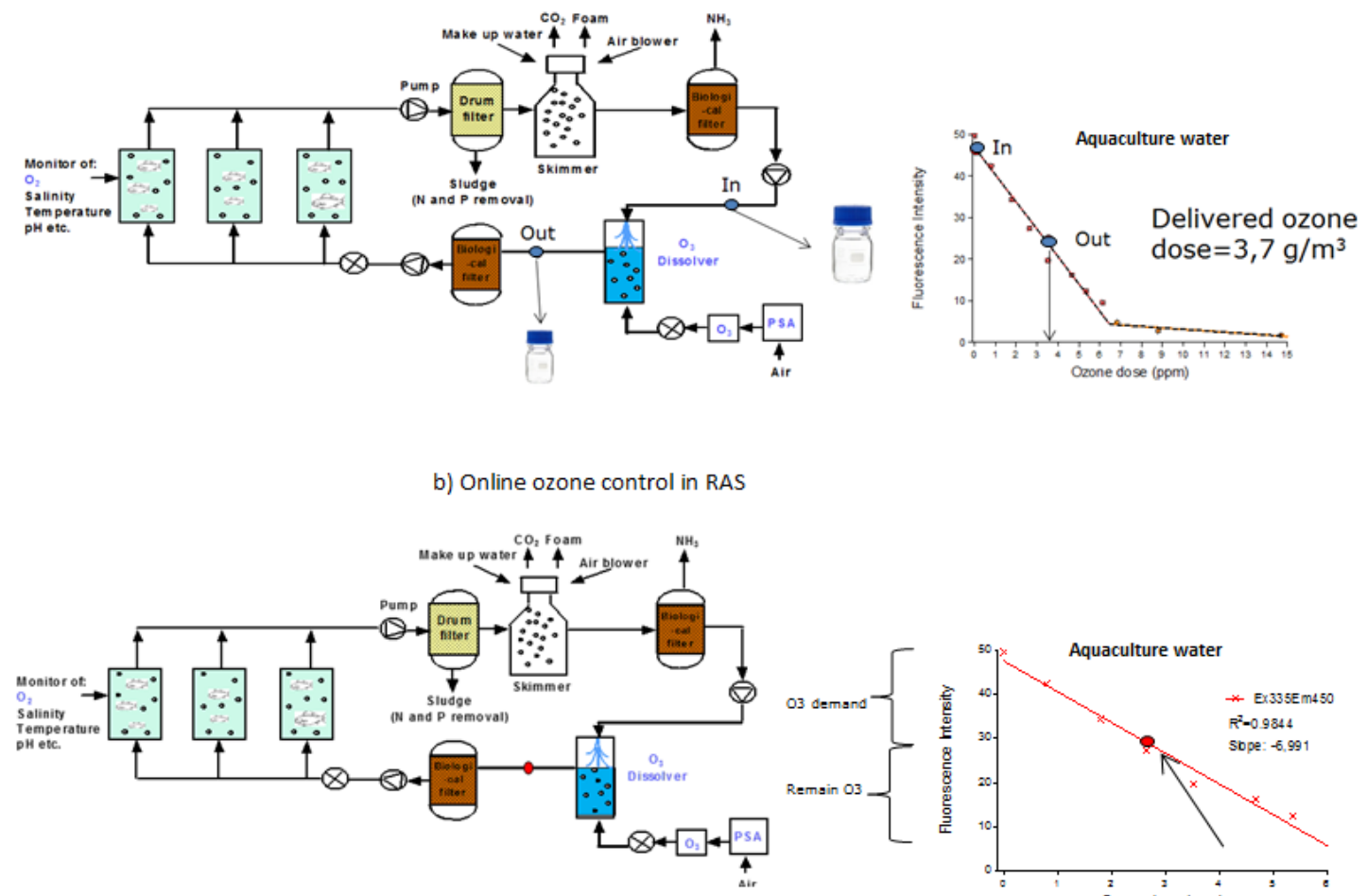

c) Online ozone control in flow-through systems
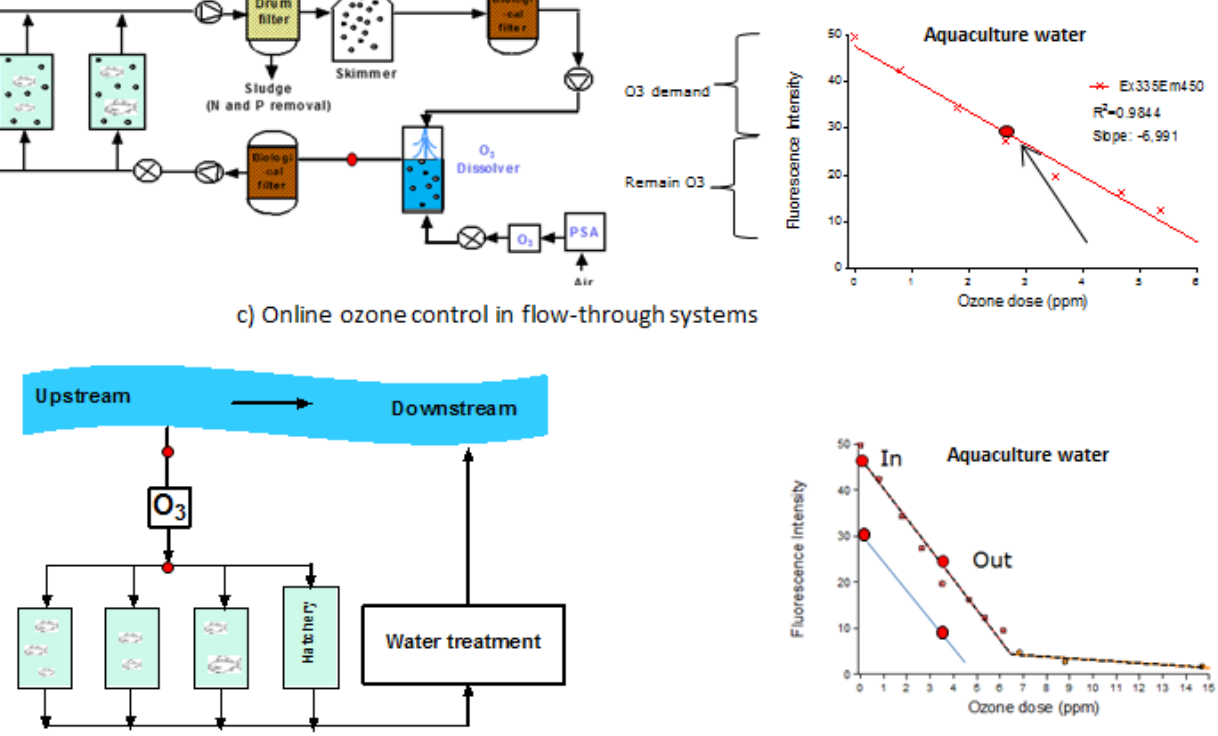

Figure 4: Schematic representation of the applications.

\section{Conclusions}

Fluorescence spectroscopy has great potential to be used as a monitoring tool to determine DOM in RASs, due to the high sensitivity to and selectivity of associated fluorophores. Consequently, low ranges (0-5 mg O3/L) can optimise ozone demand and ozone residual. The present work suggests a technique, which can be developed further in order to manufacture an accurate, low-cost and realtime measurement sensor to define ozone delivered into water. Three potential applications are suggested:

- Offline measurement, to verify ozone delivery and thus to evaluate and consequently optimise ozone system performance with a quantitative tool.

- An online sensor, used directly in an RAS, to control ozone dosage and maintain it within predetermined ranges.

- An online control sensor in flow-through systems, to control ozone dosage and maintain it within predetermined ranges. 


\section{Acknowledgements}

The authors wish to acknowledge Innovation Fund Denmark, OxyGuard International A/S and Water ApS for funding the PhD stipend for A. Spiliotopoulou. The authors are grateful to the staff of The Blue Planet, Tivoli Aquarium, DTU Aqua and the fish farms for providing water samples.

\section{Reference list}

Aiken, G.R., 2014. Fluorescence and Dissolved Organic Matter: A Chemist's Perspective, in: Aquatic Organic Matter Fluorescence. Cambridge University Press, New York, pp. 35-74.

Antoniou, M.G., Hey, G., Rodríguez Vega, S., Spiliotopoulou, A., Fick, J., Tysklind, M., la Cour Jansen, J., Andersen, H.R., 2013. Required ozone doses for removing pharmaceuticals from wastewater effluents. Sci. Total Environ. 456-457, 42-49. doi:10.1016/j.scitotenv.2013.03.072

Antoniou, M.G., Andersen, H.R., 2012. Evaluation of pretreatments for inhibiting bromate formation during ozonation. Environ. Technol. 33, 1747-1753. doi:10.1080/09593330.2011.644586

Bader, H., Hoigné, J., 1981. Determination of ozone in water by the indigo method. Water Res. doi:10.1016/0043-1354(81)90054-3

Baker, A., 2001. Fluorescence excitation - Emission matrix characterization of some sewage-impacted rivers. Environ. Sci. Technol. 35, 948-953. doi:10.1021/es000177t

Baker, A., Inverarity, R., 2004. Protein-like fl uorescence intensity as a possible tool for determining river water quality 2945, 2927-2945. doi:10.1002/hyp.5597

Bullock, G.L., Summerfelt, S.T., Noble, A.C., Weber, A.L., Durant, M.D., Hankins, J.A., 1997. Ozonation of a recirculating rainbow trout culture system. I. Effects on bacterial gill disease and heterotrophic bacteria. Aquaculture. doi:10.1016/S0044-8486(97)00063-X

Carstea, E.M., Baker, A., Bieroza, M., Reynolds, D., 2010. Continuous fluorescence excitation-emission matrix monitoring of river organic matter. Water Res. 44, 5356-5366. doi:10.1016/j.watres.2010.06.036

Carstea, E.M., Bridgeman, J., Baker, A., Reynolds, D.M., 2016. Fluorescence spectroscopy for wastewater monitoring: A review. Water Res. doi:10.1016/j.watres.2016.03.021

Chen, R.F., 1999. In situ fluorescence measurements in coastal waters. Org. Geochem. 30, 397-409. doi:10.1016/S0146-6380(99)00025-X

Coble, P.G., 1996. Characterization of marine and terrestrial DOM in seawater using excitation-emission matrix spectroscopy. Mar. Chem. 51, 325-346. doi:10.1016/0304-4203(95)00062-3

Conmy, R.N., Coble, P.G., Del Castillo, C.E., 2004. Calibration and performance of a new in situ multichannel fluorometer for measurement of colored dissolved organic matter in the ocean. Cont. Shelf Res. 24, 431-442. doi:10.1016/j.csr.2003.10.010

Cumberland, S., Bridgeman, J., Baker, A., Sterling, M., Cumberland, S., Bridgeman, J., Baker, A., Sterling, M., 2012a. Fluorescence spectroscopy as a tool for determining microbial quality in potable water applications 3330. doi:10.1080/09593330.2011.588401

Cumberland, S., Bridgeman, J., Baker, A., Sterling, M., Ward, D., 2012b. Fluorescence spectroscopy as a tool for determining microbial quality in potable water applications. Environ. Technol. 33, 687-693. doi:10.1080/09593330.2011.588401

Dalsgaard, J., Pedersen, P.B., 2011. Solid and suspended/dissolved waste (N, P, O) from rainbow trout (Oncorynchus mykiss). Aquaculture 313, 92-99. doi:10.1016/j.aquaculture.2011.01.037

Davidson, J., Good, C., Welsh, C., Brazil, B., Summerfelt, S., 2009. Heavy metal and waste metabolite accumulation and their potential effect on rainbow trout performance in a replicated water reuse system operated at low or high system flushing rates. Aquac. Eng. doi:10.1016/j.aquaeng.2009.04.001

Davidson, J., Good, C., Welsh, C., Summerfelt, S., 2011. The effects of ozone and water exchange rates on water quality and rainbow trout Oncorhynchus mykiss performance in replicated water recirculating systems. Aquac. Eng. doi:10.1016/j.aquaeng.2011.04.001

Gonçalves, A.A., Gagnon, G.A., 2011. Ozone Application in Recirculating Aquaculture System: An Overview. doi:10.1080/01919512.2011.604595

Grguric, G., Trefry, J.H., Keaffaber, J.J., 1994. Ozonation products of bromine and chlorine in seawater aquaria. Water Res. doi:10.1016/0043-1354(94)90194-5 
Hambly, A.C., Arvin, E., Pedersen, L.F., Pedersen, P.B., Seredy??ska-Sobecka, B., Stedmon, C.A., 2015. Characterising organic matter in recirculating aquaculture systems with fluorescence EEM spectroscopy. Water Res. 83, 112-120. doi:10.1016/j.watres.2015.06.037

Hansen, K.M.S., Spiliotopoulou, A., Chhetri, R.K., Escolà Casas, M., Bester, K., Andersen, H.R., 2016. Ozonation for source treatment of pharmaceuticals in hospital wastewater - Ozone lifetime and required ozone dose. Chem. Eng. J. doi:10.1016/j.cej.2016.01.027

Henderson, R.K., Baker, A., Murphy, K.R., Hambly, A., Stuetz, R.M., Khan, S.J., 2009. Fluorescence as a potential monitoring tool for recycled water systems: A review. Water Res. doi:10.1016/j.watres.2008.11.027

Hiroaki Matsuda a, Youki Ose b, Takahiko Sato c, H.N.H.K. c and K.S., 1992. Mutagenicity from ozonation of humic substances 118, 521-529.

Hudson, Naomi; Baker, Andy; Reynolds, D., 2007. Fluorescence analysis of dissolved organic matter in natural, waste and polluted waters - a review. River Res. Appl. 23, 631-649. doi:10.1002/rra

Hudson, N., Baker, A., Ward, D., Reynolds, D.M., Brunsdon, C., Carliell-Marquet, C., Browning, S., 2008. Can fluorescence spectrometry be used as a surrogate for the Biochemical Oxygen Demand (BOD) test in water quality assessment? An example from South West England. Sci. Total Environ. 391, 149-158. doi:10.1016/j.scitotenv.2007.10.054

Jin, P., Jin, X., Bjerkelund, V.A., Østerhus, S.W., Wang, X.C., Yang, L., 2016. A study on the reactivity characteristics of dissolved ef fl uent organic matter ( EfOM ) from municipal wastewater treatment plant during ozonation. Water Res. 88, 643-652. doi:10.1016/j.watres.2015.10.060

Korshin, G. V, Kumke, M.U., Li, C.-W., Frimmel, F.H., 1999. Influence of chlorination on chromophoress and fluorophores in humic substances. Environ. Sci. Technol. 33, 1207-1212.

Larsen, L.G., Aiken, G.R., Harvey, J.W., Noe, G.B., Crimaldi, J.P., 2010. Using fluorescence spectroscopy to trace seasonal DOM dynamics, disturbance effects, and hydrologic transport in the Florida Everglades. J. Geophys. Res. Biogeosciences 115, 1-14. doi:10.1029/2009JG001140

Li, W.-T., Majewsky, M., Abbt-Braun, G., Horn, H., Jin, J., Li, Q., Zhou, Q., Li, A.-M., 2016. Application of portable online LED UV fluorescence sensor to predict the degradation of dissolved organic matter and trace organic contaminants during ozonation. Water Res. doi:10.1016/j.watres.2016.05.090

Liu, C., Tang, X., Kim, J., Korshin, G. V., 2015. Formation of aldehydes and carboxylic acids in ozonated surface water and wastewater: A clear relationship with fluorescence changes. Chemosphere. doi:10.1016/j.chemosphere.2014.12.054

Powell, A., Chingombe, P., Lupatsch, I., Shields, R.J., Lloyd, R., 2015. The effect of ozone on water quality and survival of turbot (Psetta maxima) maintained in a recirculating aquaculture system. Aquac. Eng. doi:10.1016/j.aquaeng.2014.11.005

Powell, A., Scolding, J.W.S., 2016. Direct application of ozone in aquaculture systems 1-15. doi:10.1111/raq.12169

Reynolds, D.M., Ahmad, S.R., 1997. Rapid and direct determination of wastewater BOD values using a fluorescence technique. Water Res. 31, 2012-2018. doi:10.1016/S0043-1354(97)00015-8

Summerfelt, S.T., Hochheimer, J.N., 1997. Review of Ozone Processes and Applications as an Oxidizing Agent in Aquaculture. Progress. Fish-Culturist 59, 94-105. doi:10.1577/15488640(1997)059<0094:ROOPAA > 2.3.CO;2

Summerfelt, S.T., Sharrer, M.J., Hollis, J., Gleason, L.E., Summerfelt, S.R., 2004. Dissolved ozone destruction using ultraviolet irradiation in a recirculating salmonid culture system, in: Aquacultural Engineering. doi:10.1016/j.aquaeng.2004.06.004

Summerfelt, S.T., Sharrer, M.J., Tsukuda, S.M., Gearheart, M., 2009. Process requirements for achieving full-flow disinfection of recirculating water using ozonation and UV irradiation. Aquac. Eng. doi:10.1016/j.aquaeng.2008.10.002

Tango, M.S., Gagnon, G.A., 2003. Impact of ozonation on water quality in marine recirculation systems. Aquac. Eng. 29, 125-137. doi:10.1016/S0144-8609(03)00061-X

Vodacek, A., Philpot, W.D., 1987. Environmental effects on laser-induced fluorescence spectra of natural waters. Remote Sens. Environ. 21, 83-95. doi:10.1016/0034-4257(87)90008-3

Wert, E.C., Neemann, J.J., Rexing, D.J., Zegers, R.E., 2008. Biofiltration for removal of BOM and residual ammonia following control of bromate formation. Water Res. 42, 372-378. doi:10.1016/j.watres.2007.07.028 